\title{
Applications of Chicken Egg Yolk Antibodies (Igy) in Healthcare: A Review
}

\author{
Rajeswari $S^{1}$, Ankit Choraria ${ }^{1}$, Xiao-Ying Zhang ${ }^{2}$ and Michael Antonysamy*1 \\ ${ }^{1}$ Department of Micorbiology, PSG College of Arts \& Science, India \\ ${ }^{2}$ College of Veterinary Medicine, Northwest A\&F University, China
}

Received: January 02, 2018; Published: January 10, 2018

*Corresponding author: Michael Antonysamy, Department of Micorbiology, Immunotechnology Laboratory, PSG College of Arts \& Science, Coimbatore, India, Tel: 9842223414; Email: amichela2000@gmail.com

\section{Abstract}

Avian eggs are the largest source of major nutrients which consists of various types of proteins, fats, vitamins, growth factors and minerals that are required for the developing embryo and also significant number of defence factors for protecting against many viral and bacterial infections. It also consists of various biological substances in it that forms the basic unit of life. Chicken egg yolk contains antibodies called Immunoglobulin Y (IgY) which is the major antibody present in birds, lungfish, amphibia and lungfish, playing a similar role like mammalian antibody IgG. IgY antibodies are transferred from serum to egg yolk which was first demonstrated by Klemperer in 1893 [1]. This review mainly focuses on the applications of antigen-specific chicken egg yolk antibodies (IgY) in human therapeutics to protect against various bacterial and viral infections and to maintain a good care for healthy respiratory, oral and digestive system which highlights the value of human health importance and disease prevention and treatment effectively.

\section{Introduction}

Chicken egg yolk antibodies (IgY) are the functional equivalent to IgG found in mammalian serum, placenta and colostrum. In avians, the IgY antibodies are selectively transferred by certain specific receptors from the hens serum to the egg yolk [2]. One chicken egg yolk contains the actual amount of IgY equivalent to that as $30 \mathrm{ml}$ of blood/serum [3]. Due to this high quantity of consistent chicken egg yolk antibodies (IgY) and their high epitope specificity and affinity has led to the broad use of IgY antibodies in scientific and medicine therapeutic fileds. It is also found that IgY antibodies lack cross reactivity with human rheumatoid factors and they do not activate mammalian complement system, which is a major advantage for antigen-specific treatments of bacterial, fungal, viral and protozoan infections and diseases in human beings [4]. The production and amount of IgY produced from Chciken egg yolk can be affected by certain different factors, such as the breed, age, antigen used, adjuvants selected for immunization, site of immunization, maintainence, climatic conditions, chronobiological impacts and so on. It is found that the concentrations of chicken egg yolk antibodies (IgY) ranges from $2.8-7 \mathrm{mg} / \mathrm{ml}$ to upto $10 \mathrm{mg} /$ $\mathrm{ml}$ from non-specific and specific groups of chickens that are nonimmunized and immunized [3]. There are numerous studies have been conducted with antigen-specific IgY antibodies for topical and oral applications in human against various diseases [5]. Over the last 20 years, Chicken egg yolk antibodies (IgY) have received a major importance as an safe and economical source of antigenspeicific antibodies.

\section{Chicken Antibodies (IgY)}

Immunoglobulin's are classified into three different types namely IgA, IgM and IgY in Chickens that are the analogues to mammalian antibody classes. Interms of chicken antibodies, often IgG and IgY are interchanged because they are funtionally equivalent to each other and also the antibodies in hens serum is IgG and once when it is maternally transferred from hens serum to egg yolk it is called as IgY, which is an egg yolk antibody in high concentrations [6]. IgY antibodies exhibits distinct structural and functional characteristics which differentiates IgY from IgG, mammalian antibody. IgY is classified as a primitive antibody or may be a precursor to mammalian antibody and is found to have different molecular weights than other mammalian antibodies respectively. Although IgY and IgG are structurally similar, their heavy chains holds some modifications with heavier and varies antigenically that makes it to be different from IgG heavy cahins. IgY antibodies molecular weight is found to be $180 \mathrm{kDa}$ whereas, IgG vries from 180 - 150kDa. Chicken egg yolk antibodies does not bind to Fc receptors on cell surfaces having different immunological responses whereas, IgG binds to Fc receptors of specific mammalian cells [3].

\section{Why Choosing IgY?}

Egg laying Chickens like White Leghorns, as a bioreactor for large scale antibody production and becomes a cost effective source. Huge amount of acquiring antibodies and maintaining the 
Chickens becomes more easier and efficient than maintaining large number of mammals for antibody production. Chicken eggs are considered to be a daily source of large amount of nutrients and immunoglobulin's that can be efficiently collected and processed in a humane way which also proves to be very practical and inexpensive source of specific and non-specific immunoglobulin's in larger quantities effectively. Chicken egg yolk antibodies (IgY) have wider applications in diseases prevention, control and treatments where they are systematically used to treat victims of Snake venom, CPV, Rabies, Respiratory syncytial virus infections and so on [7]. It is also reported used in many other applications such as passive protection against Avian Infuenza and Rotavirus infections, potential use in preventing and treating upper respiratory tract infections and gastrointestinal infections which led to a breakthrough in passive therapy approach with Chicken egg yolk antibodies (IgY). Other studies showed the efficacy of IgY antibodies against various infections caused by coronavirus [8], Escherichia coli [9], Salmonella [10], Canine Parvo-virus [11], Helicobacter pylori [12] in gastrointestinal tracts and Pseudomonas aeruginosa infections in cystic fibrosis pateints [13], therapeutic effects in preventing dental caries [14] and also in preventing acne as an topical application. Additionally IgY antibodies have also shown its potential to be as an useful tool in cancer research and its applications.

It has a distinguished wide range of applications for several substances found in eggs, mainly in case of food, pharmaceutical and biotech industrial applications to control antibiotic resistant microbes and also to prevent them from emerging into new strains. To have a better understanding about the importance of IgY research, Chicken egg yolk antibody (IgY) has all the properties of anti-infective, especially against various infections caused by bacteria, viruses and antibiotic resistant fungi. Since, IGY being an alternative to antibiotics it can be effectively used in human and animal treatment of diseases which may play a vital role in preventing the serious global threat, the emergence of new multidrug resistant bacterias. The IgY technology is an effective, easier, environmental friendly, non-hazardous, large source and economical alternative to more pharmaceutical industries and food industries. Summary of these studies proves that the potential use of IgY antibodies in therapeutics and neutraceutical applications are wider and huge into many promising substantial benefits to be commercialized by industries and in clinical applications in both humans and animals effectively.

\section{IgY Antibodies for Therapeutic use in Healthcare Sectors for Humans}

IgY research studies has shown that the antigen-specific IgY antibodies raised against specific pathogens are effective in treating viral, bacterial and fungal diseases both in in vitro and in vivo analysis which could be immediately applicable in a straight way to humans and it does not have any toxic or harmful side effects.

\section{IgY in Digestive Care}

Rotavirus Infection: Abundant research studies with IgY antibodies therapeutic applications in humans with specific prophylaxis and therapy has been conducted globally. It has been shown that the specific antibodies against Salmonella antigens were able to inhibit their adhesion to epithelial cell linings [15]. Sarker demonstrated the action of Hyperimmune bovine colostrum (HBC) and Human rotavirus infection in children were controlled by the use of IgY in passive therapy [16]. A randomized placebocontrolled clinical trial has been conducted with specific chicken egg yolk antibodies (IgY) as an adjunct to protective therapy for rotavirus-associated diarrhea in infected children and observed for the signifcant reduction of diarrhea and the safe, effective use of specific IgY for managind acute diarrhea in the pediatric patients $[16,17]$.

Helicobacter pylori Infection: Studies with anti-Helicobacter pylori IgY antibodies has proven significant therapeutic protection in both humans [18,19] as well as in animals [20]. Specific IgY antibodies raised against particular protein of this pathogen were found to be more effective as an prophylactic agent than as an whole cell lysate and also studies shows that there were some immunodominant protein are present in Helicobacter pylori [21]. Horie et al. [12] study results showed that there is a suppressive effect of infection in 42 human volunteers with H.pylori positive after regular consumption of the functional yoghurt drink fortified with anti- urease IgY antibodies [12] and also by obtaining a significant reduction in their urea breath test effectively [19].

\section{IgY in Oral Care}

Streptococcus mutans: Dental caries is a major problem in humans and maintaining a good oral health plays a vital role in human life. Anti-Streptococcus mutans IgY was used as an effective local protection agaisnt dental plaque and dental caries and found to achieve good results as a passive protection approach to prevent and control caries [22,23]. Zhou et al. [24] tested anti-S.mutans IgY spray in adult volunteers to identify its protective effect and found that there was a significant decrease in S.mutans colonies after three weeks of IgY application [24]. Active immunization against Streptococcus mutans glucan binding protein B (GBP-B) was found to induce good protection against dental caries in experimental conditions [25]. Carlander et al. [4] studied the residual activity and the results suggest that the anti-S.mutans IgY antibodies may bind to the pathogen and prevent it from adhering to the oral cavity [4].

\section{IgY in Respiratory Care}

Pseudomonas aeruginosa: Carlander et al. [3] investigated the advantages of IgY antibodies as a prophylactic tool against Pseudomonas aeruginosa infection in Cystic fibrosis patients which is most commonly found in USA and Caucasian populations in Europe [3]. In another study 38 human volunteer patients with cystic fibrosis were made to gargle with anti-Paeruginosa IgYanibody solution for two minutes and found that prolonged use resulted in no adverse effects and none of the IgY treated patients were chronically clonized with P. aeruginosa respectively [13].

\section{Conclusion}

Chicken egg yolk antibodies (IgY) are globular proteins found in hens eggs and it is easier and possible to produce antibodies in 
large scale against vast array of pathogens and epitopes to develop antigen specific antibodies against any number of bacterial, viral and other biological agents. Numerous human and animal studies have been reported with antigen-specific IgY antibodies that are extracted from egg yolks and its significant potential for further use in immunodiagnostics and identification of disease markers, immunotherapeutics and treatment of antigen-specific infections is expected. However, more studies are needed to investigate early findings and study the benefits of $\operatorname{IgY}$ antibodies role in immune system of healthy individuals. Inspite of finding lot more benefits of IgY technology, still its universal application in both research and medicine is expected to play an increasing role in immunotherapeutics in near future.

\section{References}

1. Klemperer F (1893) Ueber natürliche Immunität und ihre Verwerthung für die Immunisirungstherapie. Archiv für Experimentelle Pathology and Pharmacology 31: 356-382.

2. Kovacs-Nolan J, Mine Y (2012) Egg yolk antibodies for passive immunity. Annu Rev Food Sci Technol 3: 163-182.

3. Carlander D, Larsson A (2001) Avian antibodies can eliminate interference due to complement activation in ELISA. Uppsala J Med Sci 106(3): 189-195.

4. Carlander D (2002) Avian IgY antibody in vitro and in vivo. Comprehensive Summaries of Uppsala Dissertations from the Faculty of Medicine 1119.

5. Mine Y, Kovacs-Nolan J (2002) Chicken egg yolk antibodies as therapeutics in enteric infectious disease: a review. Journal of Medicinal Food 5(3): 159-169.

6. Narat J (2003) Production of antibodies in chickens. Food Technol Biotechnol 41(3): 259-267.

7. Hammarström L, CIE Smith (2005) The use of intravenous IgG as prophylaxis and for treatment of infections. Infection 18(5): 314-324

8. Ikemor Y (1997) Passive protection of neonatal calves against bovine corona virus induced diarrhea by administration of egg yolk or colostrum antibody powder. Vet Micro 58(2-4): 105-111.

9. Yokoyama H, Peralta PC, Sendo R D, Ikemori Y, Kodama Y (1992) Passive protection effect of chicken egg yolk immunoglobulins against experimental enterotoxigenic escherichia coli infection in neonatal piglets. Infection \& Immunity 60(3): 998-1007.

10. Yokoyama H (1998) Prevention of fatal salmonellosis in neonatal calves using orally administrated chicken egg yolk salmonella-specific antibodies. Am J et Res 59(4): 416-420.

11. Nyguyen SV, Umeda K, Yokoyama H, Tohya Y, Kodama Y (2006) Passive protection of dogs against clinical disease due to Canine Parvovirus-2 by specific antibody from chicken egg yolk. Cdn J Vet Res 70(1): 62-64.

12. Horie K, Horie N, Abdou AM, Yang JO, Yun SS, et al. (2004) Suppressive effect of functional drinking yogurt containing specific egg yolk immunoglobulin on Helicobacter pylori in humans. Journal of Dairy Science 87(12): 4073-4079.

13. Kollberg H, Carlander D, Olesen H, Wejaker PE, Johannesson M, et al. (2003) Oral administration of specific yolk antibodies (IgY) may prevent Pseudomonas aeruginosa infections in patients with cystic fibrosis: A phase I feasibility study. Pediatric Pulmonology 35(6): 433-440.

14. Yokoyama K, Sugano N, Shimada T, Shofiqur RA, Ibrahim el SM, et al. (2007) Effects of egg yolk antibody against Porphyromonas gingivalis gingipains in periodntitis pateints. J Oral Sci 49(3): 201-206.

15. Lee EN, Sunwoo HH, Menninen K, Sim JS (2002) In vitro studies of chicken egg yolk antibody (IgY) against Salmonella enteritidis and Salmonella typhimurium. Poultry Science 81(5): 632-641.

16. Sarker SA (2001) Randomized, placebo-controlled clinical trial of hyperimmunized chicken egg yolk immunoglobulin in children with rotavirus diarrhea. Journal of Pediatric Gastroenterology \& Nutrition 32(1): 19-25.

17. Rahman S, Higo-Moriguchi K, Htun KW, Taniguchi K, Icalto FC, et al. (2012) Randomized placebo-controlled clinical trial of immunoglobulin $\mathrm{Y}$ as adjunct to standard supportive therapy for rotavirus associated diarrhea among pediatric patients. Vaccine 30(31):4661-4669.

18. Shimamoto C, Tokioka S, Hirata I, Tani H, Ohishi H, et al. (2002) Inhibition of Helicobacter pylori infection by orally administered yolk derived antiHelicobacter pylori antibody. Hepatogastroenterology 49(45): 709-714.

19. Suzuki H, Nomura S, Masaoka T, Goshima H, Kamata N, et al. (2004) Effect of dietary anti-Helicobacter pylori-urease immunoglobulin $\mathrm{Y}$ on Helicobacter pylori infection. Alimentary Pharmacology and Therapeutics 20(1): 185-192.

20. Nomura S, Suzuki H, Masaoka T, Kurabayashi K, Ishii H, et al. (2005) Effect of dietary anti-urease ommunoglobulin Y on Helicobacter pylori infection in Mongolian gerbils. Helicobacter 10(1): 43-52.

21. Shin JH, Nam SW, Kim JT, Yoon JB, Bang WG, et al. (2003) Identification of immunodominant Helicobacter pylori proteins with reactivity to H. pylori-specific egg-yolk immunoglobulin. Journal of Medical Microbiology 52(3): 217-222.

22. Hamada S, Kodoma Y (1996) Passive immunity for protection against mucosal infections and vaccination for dental caries. In Mucosal Vaccines (Eds.) H Kiyono PL Ogra, JR McGhee, Academic Press, New York, USA, pp. 187-197.

23. Hatta H, Tsuda K, Ozeki M, Kim M, Yamamoto T, et al. (1997) Passive immunization against dental plaque formation in humans: effect of a mouth rinse containing egg yolk antibodies (IgY) specific to Streptococcus mutans. Caries Research 31(4): 268-274.

24.Zhou Z, Zhou R, Tang Z (2003) Effects of topical application of immunoglobulin yolk on mutans streptococci in dental plaque. Hua Xi Kou Quiang Yi Xue Za Zhi 21(4): 295-297.

25. Nguyen SV, Icatlo FC, Nakano T, Isogai E, Hirose K, et al. (2011) Anti-cell associated glucosyltransferase immunglobulin Y suppression of salivary mutans streptococci in healthy young adults. J Am Dent Assoc 142(8): 943-949. 